\title{
Original article (short paper) \\ Assessment of motor skills and school performance in children diagnosed with attention deficit hyperactivity disorder
}

\author{
Siméia G. Palácio \\ Centro Universitário de Maringá, Maringá, PR, Brasil \\ Jorge A. De Oliveira \\ Universidade de São Paulo, São Paulo, SP, Brasil \\ Rosimeire F. Martins Arneiro \\ Hospital Santa Casa de Misericórdia de Maringá, Maringá, PR, Brasil \\ Erasmo B. Casella \\ Universidade de São Paulo, São Paulo, SP, Brasil
}

\begin{abstract}
This study was designed to analyze the association between motor skills and school performance in elementary school children with attention deficit hyperactivity disorder (ADHD). Two groups of children were evaluated. The experimental group contained 55 students of both sexes, age 7 to 10, who had been clinically diagnosed with ADHD; the control group consisted of 55 children with typical motor development. The results showed no association between motor skills and school performance in the experimental group, although there was a statistically significant difference between manual dexterity and writing performance in the control group. Although we found no relationship between motor skills and school performance in children with ADHD, we believe that having specialized professionals monitor these children may be beneficial. Early diagnosis of impaired motor skills and poor school performance may lead to better developmental opportunities and a better quality of life.
\end{abstract}

Keywords: ADHD; association; motor skills; children

\section{Introduction}

Attention deficit hyperactivity disorder (ADHD) is a neurobiological condition characterized by inattention, motor hyperactivity, and impulsivity and associated with emotional, perceptual, and motor disorders. ADHD is most frequently detected in schoolage children ${ }^{1}$ and affects about $5.29 \%$ of the global population ${ }^{2,3}$.

Clinical and epidemiological studies ${ }^{4-7}$ have shown that $30 \%$ to $50 \%$ of children diagnosed with ADHD have some form of motor skills disorder, which can negatively affect their physical, emotional, and academic development, thereby impacting the child's quality of life as well as that of the family members who care for the child.

Several authors have emphasized the relationship between motor and cognitive development in children, noting that welldeveloped motor skills are fundamental for satisfactory school performance, such as reading, arithmetic, and writing ${ }^{8,9}$. This relationship is logical, as the cerebellum and frontal lobe function together to produce coordination and cognition. Vuijik, Hartman, Mombarg, Scherder, and Visscher ${ }^{10}$ found a positive correlation between learning difficulties, ADHD, and autism in children age 7 to 12 years. They also observed that children with the greatest learning difficulties had the poorest motor skills. Using the Movement Assessment Battery for Children (MABC-2), they found associations between balance and arithmetic abilities as well as between aiming, catching, and reading.
Likewise, when Westendorp, Hartman, Houwen, Smith, and Visscher ${ }^{11}$ compared the motor skills of 120 children age 7 to 12 with and without learning difficulties, they found relationships between reading and motor skills and between arithmetic and object control skills in children with learning difficulties.

Intervention-oriented studies have shown that motor skill enhancement positively impacts school development ${ }^{12,13}$. However, most previous studies have focused only on motor skill development and general school performance; they have not tested the relationships between specific motor skills and different types of school performance, such as reading, writing, and arithmetic ${ }^{10}$. In general, studies analyzing specific relationships between motor and academic performance in children with ADHD are limited; more commonly, researchers have analyzed each of the two performance categories separately or only mentioned the existence of these difficulties. Early identification of motor deficits as a concomitant of school deficits can provide individuals with a greater chance of success and therefore a better quality of life by enabling the application of suitable interventions for this population in both health and education, thus minimizing the potential impact of the presented deficits? With this assumption in mind, the aim of the present study was to analyze the association between motor and school performance in elementary school children with and without ADHD. 


\section{Materials and methods}

\section{Subjects}

We conducted a cross-sectional study. The experimental group contained 55 children, age 7 to 10 years, who had been diagnosed with ADHD without comorbidities other than oppositional defiant disorder (ODD). We also employed a control group of 55 children with typical development who were achieving average school performance. We selected all participating children from 20 public schools in Maringá, Paraná, Brazil. The exclusion criteria for both groups included mental retardation, inability to read and/or write, and severe hearing, visual, heart, neuropsychiatric, rheumatic, or orthopedic disorders.

Written consent was obtained from the parents and/or caregivers of all participants, and the study was approved by the Ethics and Research Committee of the University of Sao Paulo Faculty of Medicine (no. 030711).

\section{Procedures}

Children with ADHD were identified via an initial screening of 1,484 children. In this first phase, teachers and parents were asked to complete the SNAP-IV questionnaire (14). By analyzing the responses to the SNAP-IV, we identified 83 children with possible ADHD. These children were referred to a pediatric neurologist, who used the diagnostic criteria from the Diagnostic and Statistical Manual of Mental Disorders, Fourth Edition (DSM-IV) to confirm a clinical diagnosis of ADHD without comorbidities (except ODD) and identify the corresponding clinical ADHD Subtype ${ }^{15}$.

After assessment by the pediatric neurologist, 55 of the children were included in the experimental group. Of these, 31 children were diagnosed with the combined subtype (56.4\%), 22 with the inattentive subtype (40\%), and 2 with the hyperactive impulsive subtype $(3.6 \%)$ of ADHD.

We also selected 55 children for the control group who were free of ADHD symptoms according to data from the SNAP-IV questionnaire. The sociodemographic data for the children in both groups are shown in Table 1 .

The first author of this study then assessed the motor skills and school performance of the children in both groups.

Table 1: Sociodemographic characteristics of the participant sample

\begin{tabular}{llllll}
\hline \multirow{2}{*}{ Variables } & Categories & \multicolumn{2}{c}{$\begin{array}{c}\text { Experimental } \\
\text { Group } \\
(\mathbf{n}=\mathbf{5 5})\end{array}$} & $\begin{array}{c}\text { Control Group } \\
(\mathbf{n}=\mathbf{5 5})\end{array}$ \\
\hline \multirow{2}{*}{ Sex } & $\mathbf{N}^{\mathbf{a}}$ & $\mathbf{\%}^{\mathbf{b}}$ & $\mathbf{N}^{\mathbf{a}}$ & $\mathbf{\%}^{\mathbf{b}}$ \\
\hline \multirow{2}{*}{ Age } & Male & 38 & $69.1 \%$ & 38 & $69.1 \%$ \\
\hline \multirow{2}{*}{ School Grade } & Female & 17 & $30.9 \%$ & 17 & $30.9 \%$ \\
\cline { 2 - 6 } & 9-8 years & 32 & $58.2 \%$ & 32 & $58.2 \%$ \\
\cline { 2 - 6 } & Second grade & 23 & $41.8 \%$ & 23 & $41.8 \%$ \\
\cline { 2 - 6 } & Third grade & 18 & $32.7 \%$ & 18 & $32.7 \%$ \\
\hline
\end{tabular}

${ }^{a} \mathrm{~N}=$ number of children

b $\%=$ percentage of children
Of the 55 children diagnosed with ADHD, 50 were treatmentnaïve and 5 were being treated with psychostimulant medications. We asked the parents or guardians of these 5 children to discontinue their medication for 48 hours before the motor and school performance tests.

We used the Movement Assessment Battery for Children 2 (MABC-2) to evaluate the participants' motor skills. The MABC-2 is a standard test used to identify and describe motor skills in children age $3-16$. For this study, we used the tests that are considered appropriate for children age 7 to $10^{16}$.

The MABC-2 assesses skills in three categories: manual dexterity, aiming and catching, and static and dynamic balance. The scores for these three groups are summed, resulting in a total score that is then converted into a corresponding percentile ranking. A total score at or below the 5 th percentile indicates significant motor difficulty; scores from the 6th to the 15 th percentile are associated with borderline motor difficulty; and a score at or above the 16 th percentile indicates no motor difficulty.

We used the School Performance Test (SPT) to assess reading, writing, and arithmetic performance in both groups. This test is generally used to evaluate elementary school students, and it rates their performance as good, average, or poor ${ }^{17}$. On the SPT, writing is assessed by asking the student to write words dictated to him or her; arithmetic is assessed by means of the performance of mathematical operations orally or in writing; and the reading assessment is based on the degree of understanding of isolated words presented out of context.

\section{Statistical analysis}

We generated descriptive statistics for all variables using $\mathrm{R}$ for Windows $\mathrm{FAQ}^{18}$. The level of statistical significance was set at $5 \%(p \leq 0.05)$. We used Fischer's exact test to compare school performance in both groups as well as motor and school performance according to clinical ADHD subtype.

We used the chi-squared test to assess the relationship between motor performance classification and group membership. We also used the Spearman correlation coefficient to analyze the relationship between motor skills and school performance, and the Mann-Whitney test to compare MABC-2 scores in both groups.

\section{Results}

The school performance results, shown in Table 2, revealed statistically significant differences between the two groups in terms of reading ( $p=0.001)$, writing $(p=0.002)$, and the total raw score on the SPT $(p<0.0001)$.

As for motor performance, a medians analysis revealed no statistically significant differences between the groups for all variables analyzed, although both groups exhibited deficient balance skills (Table 3).

Total MABC- 2 scores revealed that there were twice as many children with borderline or significant motor difficulty in the experimental group as in the control group (Table 4). 
Table 2: Frequency $(\mathrm{N})$ and percentage (\%) of students by group who were classified into good, average, or poor school performance categories via the School Performance Test (SPT)

\begin{tabular}{|c|c|c|c|c|c|}
\hline \multirow{2}{*}{ Variables } & \multirow{2}{*}{ Group } & Good & Average & Poor & \multirow{2}{*}{$\mathbf{p}$} \\
\hline & & N (\%) & N (\%) & N (\%) & \\
\hline \multirow{2}{*}{ Writing } & Experimental & $10(18.2 \%)$ & $23(41.8 \%)$ & $22(40.0 \%)$ & \multirow{2}{*}{$0.002 *$} \\
\hline & Control & $15(27.3 \%)$ & $34(61.8 \%)$ & $6(10.9 \%)$ & \\
\hline \multirow{2}{*}{ Arithmetic } & Experimental & $28(51.0 \%)$ & $19(34.5 \%)$ & $8(14.5 \%)$ & \multirow{2}{*}{0.137} \\
\hline & Control & $32(58.2 \%)$ & $21(38.2 \%)$ & $2(3.6 \%)$ & \\
\hline \multirow{2}{*}{ Reading } & Experimental & $3(5.4 \%)$ & $29(52.7 \%)$ & $23(42.0 \%)$ & \multirow{2}{*}{$0.001^{*}$} \\
\hline & Control & $17(31.0 \%)$ & $25(45.4 \%)$ & $13(23.6 \%)$ & \\
\hline \multirow{2}{*}{$\mathrm{SPT}^{\mathrm{a}}$} & Experimental & $7(12.7 \%)$ & $22(40.0 \%)$ & $26(47.3 \%)$ & \multirow{2}{*}{$<0.0001 *$} \\
\hline & Control & $20(36.4 \%)$ & $32(58.2 \%)$ & $3(5.4 \%)$ & \\
\hline
\end{tabular}

${ }^{a}$ School Performance Test, raw score total

${ }^{*} p \leq 0.05$

Table 3: MABC-2 test results for the experimental and control groups, shown as percentiles

\begin{tabular}{|c|c|c|c|}
\hline Variables & Group & $\operatorname{Median}\left(\mathbf{Q 1}^{\mathrm{a}} ; \mathbf{Q 3}^{\mathrm{b}}\right)$ & $\mathbf{p}$ \\
\hline \multirow{2}{*}{ Manual dexterity } & Experimental & $37(09-63)$ & \multirow{2}{*}{0.95} \\
\hline & Control & $37(09-63)$ & \\
\hline \multirow{2}{*}{ Aiming and catching } & Experimental & $37(16-63)$ & \multirow{2}{*}{0.103} \\
\hline & Control & $50(25-75)$ & \\
\hline \multirow{2}{*}{ Balance } & Experimental & $25(05-63)$ & \multirow{2}{*}{0.409} \\
\hline & Control & $25(09-50)$ & \\
\hline \multirow{2}{*}{ Total score } & Experimental & $25(09-63)$ & \multirow{2}{*}{0.756} \\
\hline & Control & $25(16-50)$ & \\
\hline
\end{tabular}

${ }^{\mathrm{a}} \mathrm{Q} 1=25$ th percentile

${ }^{\mathrm{b}} \mathrm{Q} 3=75$ th percentile

Table 4: Distribution of frequency (N) and percentages (\%) of children with various motor difficulty classifications

\begin{tabular}{|c|c|c|c|c|}
\hline Variables & Group & $\begin{array}{l}\text { No motor difficulty } \\
(\mathbf{n} ; \%)\end{array}$ & $\begin{array}{l}\text { Borderline and significant } \\
\text { motor difficulty (n; \%) }\end{array}$ & $p$ \\
\hline \multirow{2}{*}{ Manual Dexterity } & Experimental & $42(76.4 \%)$ & $13(23.6 \%)$ & \multirow{2}{*}{0.516} \\
\hline & Control & $39(70.9 \%)$ & $16(29.1 \%)$ & \\
\hline \multirow{2}{*}{ Aiming and catching } & Experimental & $47(85.5 \%)$ & $08(14.5 \%)$ & \multirow{2}{*}{0.376} \\
\hline & Control & $50(90.9 \%)$ & $05(9.1 \%)$ & \\
\hline \multirow{2}{*}{ Balance } & Experimental & $29(52.7 \%)$ & $26(47.3 \%)$ & \multirow{2}{*}{0.175} \\
\hline & Control & $36(65.5 \%)$ & $19(34.5 \%)$ & \\
\hline \multirow{2}{*}{ Total Score } & Experimental & $37(67.3 \%)$ & $18(32.7 \%)$ & \multirow{2}{*}{$0.046^{*}$} \\
\hline & Control & $46(83.6 \%)$ & $09(16.4 \%)$ & \\
\hline
\end{tabular}


Compared with the control group, our analysis of motor performance by members of the experimental group did not reveal any statistically significant differences in manual dexterity (MD) skills $(p=0.863)$, aiming and catching (A\&C) $(p=0.567)$, balance (B) $(p=0.174)$, or total MABC-2 score. Additionally, we found no statistically significant differences in writing $(p=0.605)$, reading $(p=0.734)$, arithmetic $(p=0.931)$, or total raw score on the SPT $(p=0.928)$ between the two groups.

When assessing the relationship between motor and school performance (Table 5) in both groups, we found a statistically significant correlation between manual dexterity and writing performance $(p=0.010)$ in the control group only.

Table 5: Correlation ( $r$ ) between motor and school performance in the experimental and control groups

\begin{tabular}{|c|c|c|c|c|c|}
\hline & Group & & MD & $A \& C$ & B \\
\hline \multirow{2}{*}{ Writing } & Experimental & $\begin{array}{l}r \\
p\end{array}$ & $\begin{array}{r}-.112 \\
.414\end{array}$ & $\begin{array}{c}-.019 \\
.890\end{array}$ & $\begin{array}{l}.102 \\
.457\end{array}$ \\
\hline & Control & $\begin{array}{l}r \\
p\end{array}$ & $\begin{array}{c}.346 \\
.010 *\end{array}$ & $\begin{array}{l}.126 \\
.357\end{array}$ & $\begin{array}{l}.054 \\
.697\end{array}$ \\
\hline \multirow{2}{*}{ Arithmetic } & Experimental & $\begin{array}{l}r \\
p\end{array}$ & $\begin{array}{c}-.224 \\
.100\end{array}$ & $\begin{array}{l}.190 \\
.164\end{array}$ & $\begin{array}{l}.061 \\
.659\end{array}$ \\
\hline & Control & $\begin{array}{l}r \\
p\end{array}$ & $\begin{array}{l}.096 \\
.484\end{array}$ & $\begin{array}{l}.261 \\
.054\end{array}$ & $\begin{array}{r}-.134 \\
.328\end{array}$ \\
\hline \multirow{2}{*}{ Reading } & Experimental & $\begin{array}{l}r \\
p\end{array}$ & $\begin{array}{c}-.108 \\
.433\end{array}$ & $\begin{array}{l}.056 \\
.687\end{array}$ & $\begin{array}{l}.180 \\
.190\end{array}$ \\
\hline & Control & $\begin{array}{l}r \\
p\end{array}$ & $\begin{array}{c}-.159 \\
.246 \\
\end{array}$ & $\begin{array}{l}.086 \\
.534 \\
\end{array}$ & $\begin{array}{l}.039 \\
.776 \\
\end{array}$ \\
\hline
\end{tabular}

Note. $\mathrm{MD}=$ manual dexterity; $\mathrm{A} \& \mathrm{C}=$ aiming and catching; $\mathrm{B}=$ balance. ${ }^{*} p \leq 0.05$

\section{Discussion}

Our main objective was to analyze the association between motor and school performance in children with and without ADHD who are enrolled in public elementary schools in Maringá, Paraná, Brazil. We found that a greater percentage of children in the experimental group exhibited motor performance at or below the 15 th percentile $(n=18,32.7 \%)$, compared with those in the control group $(n=9,16.4 \%)$. This finding is consistent with other clinical studies, such as those conducted by Fliers et al. ${ }^{6}$ and Goulardins, Marques, Casella, Nascimento, and Oliveira $^{19}$, who found that $30 \%$ to $50 \%$ of their study population exhibited motor deficits. This result was expected, given the existing literature on frontal striatal circuit dysfunction in children with ADHD.

Five children in the experimental group were being treated with psychostimulant medications, which had scores on motor performance ranging from $6^{\text {th }}$ to $15^{\text {th }}$ percentiles. However, the percentage of motor-impaired children in the control group (16.4\%) was higher than typical estimates for the normal population $(6 \%)$, according to the existing literature ${ }^{15}$. This inconsistency may be due to individual differences in physical biotype, sociocultural level, the nature of physical education classes, the amount of stimulation at home, increases in the amount of time spent watching television and using computers, dependence on motor vehicles for travel rather than walking or biking, or high levels of urban violence, which encourage children to stay at home.

According to Seidman et al. ${ }^{20}$, motor immaturity in children with ADHD may be related to a delay in cortical maturation, especially in prefrontal areas related to attention, working memory, and motor control accuracy. Other frontal areas, such as the premotor and motor cortex, are also related to activities involved in MABC-2 motor tests. These include aiming, catching, and jumping, as these activities involve fast sequential movements ${ }^{21}$.

Of all the abilities tested by the MABC-2, balance skills were the poorest in both the experimental and control groups. Some authors have suggested that balance deficits in children with ADHD are related to low cerebellum volume and corresponding abnormalities in the associated circuits, which include the prefrontal cortex and basal ganglia ${ }^{22}$.

Balance deficits in children with ADHD were also noted in the study by Goulardins, Marques, Casella, Nascimento, Oliveira $^{19}$, who used the Motor Development Scale (MDS) to find statistically significant differences in balance between a group of boys with combined ADHD and a control group. However, we did not observe this phenomenon. This variation in results may be due to the different assessment tools used, as the MDS contains subtests with various degrees of complexity, or a consequence of the different kinds of sample populations employed. Specifically, Goulardins et $\mathrm{al}^{2}$. used a clinical population, whereas our participants were recruited from schools.

Kooistra, Crawford, Dewey, Cantell, and Kaplan ${ }^{23}$ suggested that the motor problems frequently seen in children with ADHD may be more strongly related to comorbidities of ADHD, rather than ADHD itself. They tested fine and gross motor skills in 486 children with ADHD using the Bruininks-Oseretsky Test of Motor Proficiency (BOTMP), finding that the general motor performance of children with ADHD was similar to that of the control group. Although this test was different from the one used in the present study, the researchers obtained similar results with respect to motor skills.

With respect to motor performance in individuals with different ADHD subtypes, Martin, Levy, Pieka, and Hay ${ }^{24}$ found a relationship between the predominant inattentive subtype and problems with fine motor skills. It is possible that we did not find this association due to our limited sample size for each clinical subtype.

In our study, $40 \%$ of the children with ADHD and $9.1 \%$ of the control children exhibited criteria for learning difficulties according to the SPT. Stein ${ }^{17}$, author of the SPT, estimated that $25 \%$ of children with typical motor development have learning difficulties, which is substantially higher than the $9.1 \%$ rate found in our control group. However, the percentage of our ADHD group who exhibited learning difficulties matched the range mentioned by DuPaul, Gormley, and Laracy ${ }^{25}$, i.e., $31-45 \%$.

Learning difficulties in children with ADHD appear to stem predominantly from neuropsychological deficits in attention and executive functioning ${ }^{2,26}$, deficits in inhibitory control, and a longer reaction time ${ }^{27}$.

Although studies have reported a higher rate of learning difficulties in individuals with inattentive $\mathrm{ADHD}^{28,29}$, we found that 
such difficulties were manifest in all ADHD subtypes $(p>0.05)$. This is similar to the findings of Beltrame, Silva, and Staviski ${ }^{30}$, who assessed schoolchildren age 10 to 12 who were suspected of having ADHD $(p=0.061)$. This result, which contradicts most studies, might be attributed to our limited sample size.

Among all areas analyzed by the SPT, children from both groups had their best performance in arithmetic skills (despite participants in the experimental group had lower scores than the control group). According to Casas, Alba, and Taverner ${ }^{31}$, children who had ADHD without associated comorbidities did not appear to have difficulty with calculations or solving arithmetic problems. However, both their study and the present investigation sampled children with ADHD who were recruited from schools, and this fact may have contributed to the similarity in the observed results.

In terms of the relationship between motor skills and school performance, we found a slight association between writing and manual dexterity in the control group only. This is logical, as writing is related to fine motor development and requires a high degree of accuracy ${ }^{32,33}$.

Unexpectedly, we found that motor skills and school performance were not related. This finding was also reported by Beltrame, Silva, and Staviski ${ }^{30}$, even though many other studies have indicated contrary results. This difference may be related to the way in which other studies classified school performance; for example, in the present study we evaluated children that had average academic performance, whereas other studies may have only assessed children with poor performance.

The results of the present study must be interpreted carefully. We found that the frequency of motor problems (borderline or significant motor difficulty) observed in our experimental group, although the diagnosis has been made by a paediatric neurologist, and the child was not examined in a clinic but in school the child attended. These diagnoses were not higher than the general population.

\section{Limitations and considerations for future research}

Limitations of the present study include the lack of qualitative analysis regarding motor performance and the small sample size. Perhaps these may have limited the statistical power of our tests, making it less likely that we would detect possible differences between the groups.

Another limitation we found were statistically significant differences in reading and writing between the groups studied. Specifically, there were significant differences in the total raw score on the School Performance Test and in the level of motor difficulty between children with ADHD and controls. It may be helpful to have specialized professionals monitor the motor and school performance of children with ADHD. Early diagnosis of such difficulties could reduce the potential for their impairment to negatively impact motor skill development and school performance, thus offering these children better developmental opportunities and a better quality of life. Further research with larger sample populations is needed.

\section{References}

1. Halperin J, Healey DM. The influences of environmental enrichment, cognitive enhancement, and physical exercise on brain developmental: Can we alter the developmental trajectory of ADHD? Neurosci Biobeha Rev. 2011; 35(3):621-34.

2. Goulardins JB, Rigoli D, Loh PR, Kane R, Licari M, Hands B, Oliveira JA, Piek J. The Relationship Between Motor Skills, Social Problems, and ADHD Symptomatology: Does It Vary According to Parent and Teacher Report? J Of Atten Disorders. 2015; 19:1-10.

3. Polanczyk G, de Lima MS, Horta BL, Biederman J, Rohde LA. The worldwide prevalence of ADHD: a systematic review and metaregression analysis. Am J Psychiatry. 2007; 164(6):942-948

4. Polatajko HJ, Cantin N. Developmental coordination disorder (dyspraxia): an overview of the state of the art. Semin Pediatr Neurol. 2005; 12:250-258.

5. Magalhães LC, Missiuna C, Wong S. Terminology used in research reports of developmental coordination disorder. Dev Med Child Neurol. 2006; 48:937-941.

6. Fliers EA, Franke B, Lambregts-Rommelse NNJ, Altinki ME, Buschgens CJM, Nijhuis-van der Sanden MW, Sergeant JA, Faraone SV, Buitelaar JK. Undertreatment of Motor Problems in Children with ADHD. Child Adolesc Ment Health. 2009; 15(2):85-90.

7. Marques JC, Oliveira JA, Goulardins JB, Nascimento RO, Vaz de Lima AM, Casella EB. Comparison of child self-reports and parent proxy-reports on quality of life of children with attention deficit hyperactivity disorder. Health Qual Life Outcomes. 2013; 11:186.

8. Viholainen H, Ahonen T, Lyytinen P, Cantell M, Tolvanen A, Lyytinen H. Early motor development and later language and reading skills in children at risk of familial dyslexia. Dev Med Child Neurol. 2006; 48:367-373.

9. Piek J, Dawson L, Smith LM, Gasson N. The role of early fine and gross motor development on later motor and cognitive ability. Hum Movement Sci. 2008; 27(5):668-681.

10. Vuijk PJ, Hartman E, Mombarg R, Scherder EJA, Visscher C. Associations between the academic and motor performance in a heterogeneous sample of children with learning disabilities. J Learn Disabil. 2011; 44:276-282.

11. Westendorp M, Hartman E, Houwen S, Smith J, Visscher C. The relationship between gross motor skills and academic achievement in children with learning disabilities. Res Dev Disabil. 2011; 32:2773-2779.

12. Budde H, Voelcker-Rehage, C Pietrabyk-Kendziorra S, Ribeiro P, Tidow G. Acute coordinative exercise improves attention performance in adolescents. Neurosci Lett. 2008; 441:219-223.

13. Ulrich TA, Swalm RL. A pilot study of a possible effect from a motor task on reading performance. PerMS. 2007; 104:1035-1041.

14. Matos P, Serra Pinheiro MA, Rodhe LA, Pinto D. Presentation of a Portuguese version for use in Brazil MTA-SNAP-IV instrument evaluation of 27 symptoms of attention deficit hyperactivity disorder and symptoms of defiant and oppositional disorder. Rev. psiquiatr. Rio Gd. Sul. 2006: 28(3):290-297.

15. American Psychiatric Association. Diagnostic and statistical manual of mental disorders. Fourth edition, Text revision. Washington DC, American Psychiatric Association; 2000. 
16. Henderson SE, Sugden DA, Barnett AL. Movement Assessment Battery for Children (2nd ed). San Antonio, Harcourt Assessment; 2007.

17. Stein LM. School Performance Test - (SPT). São Paulo, Phychologist's House; 1994.

18. Hornick K. (2015) R for Windows FAQ. url: \{https://www. CRAN.R-project.org/doc/FAQ/R-FAQ.html\}. Accessed: 02 February 2015.

19. Goulardins JB, Marques JCB, Casella EB, Nascimento RO, Oliveira JA. Motor profile of children with attention deficit hyperactivity disorder combined type. Res Dev Disabil. 2013; 34:40-45.

20. Seidman LJ, Valera EM, Makris N, Monuteaux MC, Boriel DL, Kelkar K, et al. Dorsolateral prefrontal and anterior cingulate cortex, volumetric abnormalities in adults with attention-deficit/ hyperactivity disorder identified by magnetic resonance imaging. Biol Psychiatry. 2006; 60(10):1071-1080.

21. Shaw P, Eckstrand K, Sharp W, Blumenthal J, Lerch J P, Greenstein $\mathrm{D}$, et al. Attention-deficit/hyperactivity disorder is characterized by a delay in cortical maturation. PNAS. 2007: 104(49):19649-19654.

22. Valera EM, Faraone SV, Murray, KE, Seidman LJ. Meta-analysis of structural imaging findings in attention-deficit /hyperactivity disorder. Biol Psychiatry. 2007; 6(12):1361-1369.

23. Kooistra L, Crawford S, Dewey D, Cantell M, Kaplan B. Motor correlates of ADHD: Contribution of Reading Disability and Oppositional Defiant Disorder. J Learn Disabil. 2005; 38(3):195-206.

24. Martin NC, Levy F, Pieka J, Hay DA. A genetic study of attention deficit hyperactivity disorder, conduct disorder, oppositional defiant disorder and reading disability: aetiological overlaps and implications. Int J Disabil, Dev Ed. 2006; 53(1):21-34.

25. DuPaul GJ, Gormley MJ, Laracy SD. Comorbidity of LD and ADHD: implications of DSM-5 for assessment and treatment. J Learn Disabil. 2013; 46(1):43-51.

26. McGrath LM, Pennington BF, Shanahan MA, Santerre-Lemmon LE, Barnard HD, Willcutt EG, Defries JC, Olson RK. A multiple deficit model of reading disability and attention-deficit/hyperactivity disorder: Searching for shared cognitive deficits. J Child Psychol Psychiatry. 2011; 52:547-557.
27. Bolfer C, Casella EB, Baldo MV, Mota A M, Tsunemi MH, Pacheco SP, et al. Reaction time assessment in children with ADHD? Arq Neuropsiquiatr. 2010; 68(2): 282-286.

28. Massetti GM, Lahey BB, Pelham WE, Loney J, Ehrhardt A, Lee $\mathrm{SS}$, et al. Academic achievement over 8 years among children who met modified criteria for attention-deficit/hyperactivity disorder at 4-6 years of age. JACP. 2008; 36:399-410.

29. Pondé MP, Cruz-Freire AC, Silveira, AA. Relationship Between Learning Problems and Attention Deficit in Childhood. J Of Atten Disorders. 2012; 19 16(6):505-509.

30. Beltrame TS, Silva J, Staviski G. Psychomotor development and academic performance of students aged 10 to 12 years with indication Attention Deficit Hyperactivity Disorder. Cinergis. 2007; 8(1): 33-39.

31. Casas AM, Alba AM, Taverner RM. Habilidades matemáticas y funcionamiento ejecutivo de niños con trastorno por déficit de atención con hiperactividad y dificultades del aprendizaje de las matemáticas. Psicothema. 2009; 21(1):63-69.

32. Feder K, Majnemer A. Handwriting Development, Competency, and Intervention. Dev Med Child Neurol. 2007; 49:312-317.

33. Goulardins JB, Rigoli D, Licari M, Piek JP, Hasue RH, Oosterlaan J, Oliveira, JA. Attention deficit hyperactivity disorder and developmental coordination disorder: Two separate disorders or do they share a common etiology. Behav Brain Res. 2015; 292:484-492.

\section{Corresponding author}

Jorge A. De Oliveira

School Physical Education and Sports / University of São Paulo (EEFEUSP), Av. Prof. Mello Moraes, 65, Butanta, São Paulo, Brazil.

Email: jadolive@usp.br

Manuscript received on March 10, 2016

Manuscript accepted on August 10, 2016

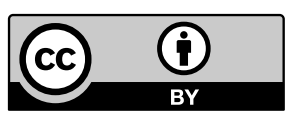

Motriz. The Journal of Physical Education. UNESP. Rio Claro, SP, Brazil - eISSN: 1980-6574 - under a license Creative Commons - Version 3.0 